\title{
Genetics of obesity in adult adoptees and their biological siblings
}

\author{
Thorkild I A Sørensen, R Arlen Price, Albert J Stunkard, Fini Schulsinger
}

\begin{abstract}
An adoption study of genetic effects on obesity in adulthood was carried out in which adoptees separated from their natural parents very early in life were compared with their biological full and half siblings reared by their natural parents. The adoptees represented four groups who by sampling from a larger population were categorised as either thin, medium weight, overweight, or obese. Weight and height were obtained for 115 full siblings of 57 adoptees and for 850 half siblings of 341 adoptees. In full siblings body mass index $\left(\mathrm{kg} / \mathrm{m}^{2}\right)$ significantly increased with weight of the adoptees. Body mass index of the half siblings showed a steady but weaker increase across the four weight groups of adoptees. There were no significant interactions with sex of the adoptees, sex of the siblings, or (for the half siblings) sex of the common parent. In contrast with the findings in half siblings and (previously) the natural parents there was a striking, significant increase in body mass index between full siblings of overweight
\end{abstract} and obese adoptees.

The degree of fatness in adults living in the same environment appears to be influenced by genetic factors independent of sex, which may include polygenic as well as major gene effects on obesity.

\section{Introduction}

Fatness runs in families, ${ }^{1-4}$ and the evidence for a genetic contribution to this tendency comes from several types of studies. ${ }^{5}$ These include fitting genetic models to the familial correlations, ${ }^{6}$ studies of twins, and studies comparing adoptees and the offspring of the adoptive parents. ${ }^{68-13}$ None, however, has excluded confounding due to environmental effects. Two recent studies of adult adoptees and their natural parents ${ }^{14}$ is have provided further evidence. The findings were compatible with additive polygenic effects, but major gene influences could not be excluded. Furthermore, in contrast with the family studies, ${ }^{1+6}$ these studies suggested a stronger genetic relation between women than between men. The studies, however, were limited owing to difficulty in ascertaining parental fatness and changes over time in environmental effects.

We report a new type of study, which compares the current body mass index of adult adoptees with that of their biological full and half siblings from whom they were reared apart. Our findings allow further assessment of the genetic contribution.

\section{Subjects and methods}

\section{ADOPTEES}

Data on every completely non-familial adoption granted in Denmark between 1924 and 1947 were transferred to the Danish Adoption Register at the Psykologisk Institut, Kommunehospitalet, in Copenhagen. ${ }^{16}{ }^{17}$ The records provide date of formal adoption, age of the child at transfer to the adoptive parents, the identity of the adoptive father and mother, and, when known, the identities of the natural parents. Paternity was established by acknowledgment or biological tests, as required by Danish law.

Valid assessment of genetic effects in an adoption study requires separation of genetic and environmental influences. This means separation of the child from the natural parents shortly after birth, negligible effect on the trait at issue of the prenatal and postnatal environments shared with the natural mother, and rearing of the child independent of the natural parents by biologically unrelated adoptive parents who are selected without regard to the trait at issue. These requirements generally appear to have been met in the Danish adoptee population..$^{1417}$

This study was based on the 5455 adoptions granted in Copenhagen. Current addresses of 4643 adoptees still living in Denmark were obtained from the local population registers, which since 1923 have filed names and addresses of every person in Denmark from birth to death or emigration. The adoptees were mailed a questionnaire asking about current height, weight, and other health issues, and $3651(79 \%)$ replied. ${ }^{14}$ Data on height and weight were complete for 3580 adoptees and were used to calculate the body mass index (weight $\left.(\mathrm{kg}) /(\text { height }(\mathrm{m}))^{2}\right)$ as a measure of fatness. ${ }^{19}$ Mean age of the adoptees was $42 \cdot 2($ SD $8 \cdot 1)$ years, and $56 \%$ were women.

Four weight groups - namely, thin, medium weight, overweight, and obese, each constituting $4 \%$ of the sample - were selected from among 3580 adoptees for further study. To minimise possible bias due to the influence of age and sex on body mass index selection of the four groups proceeded on the basis of ranked body mass index values within $5 \times 2$ age and sex strata. The thin group consisted of those between the lowest four centiles, the medium weight group those closest to the median, the overweight group those between the 92nd and 96th centiles, and the obese group those above the 96th centile. Characteristics of the 540 selected adoptees have been described. ${ }^{14}$

IDENTIFICATION AND ASCERTAINMENT OF SIBLINGS

By means of the regional population registers we traced 506 (94\%) natural mothers and 418 (77\%) natural fathers and identified 210 biological full siblings of the adoptees, 709 maternal half siblings, and 649 paternal half siblings. Follow up of the siblings by means of the registers showed that 164 full siblings, 610 maternal half siblings, and 544 paternal half siblings were currently living in Denmark.

A questionnaire requesting information on height and weight was sent to the biological siblings. Replies were received from $115(70 \%)$ of the full siblings, 466 $(76 \%)$ of the maternal half siblings, and $384(71 \%)$ of the paternal half siblings. This corresponded to 57 full sibships and 341 half sibships (255 maternal, 196 paternal; 110 sibships included both types). Table I shows the distribution of siblings over the four weight groups of adoptees. The ages of the siblings in the four weight groups were similar to those of the adoptees.

Self reported height and weight are known to show modest errors that increase with increasing body weight. ${ }^{20}$ The frequency of non-response depends in part on the degree of fatness as well as on various related psychosocial characteristics (S Sonne-Holm et al, unpublished observations). It seemed reasonable to assume that these limitations would make the results conservative estimates of the true relations. 


\section{STATISTICAL ANALYSIS}

Having adjusted for the confounding effect of age on body mass index, we assessed in hierarchical multiple linear regression analyses the relation between body mass index of the siblings and weight groups of the adoptees, sex of the siblings, sex of the adoptees, and, for the half siblings, sex of the common parents. As the body mass index of siblings is correlated, ${ }^{13}$ we adjusted the individual body mass index of siblings for size of sibships (weighted by the reciprocal of the number of siblings in the sibship and counting degrees of freedom on the basis of number of sibships). Weight groups of adoptees (thin, medium, overweight, obese) were used either as qualitative variables or, in order to assess trends across the weight groups, as a continuous variable. Statistical significance was evaluated by $F$ test and accepted at a two sided level of 0.05 .

\section{Results}

The mean body mass index of the full siblings increased with the weight group of the adoptees (thin $22 \cdot 0$, medium $22 \cdot 7$, overweight $23 \cdot 8$, obese $26 \cdot 6$ ) (figure). In the regression analysis the differences between weight groups was significant $(p<0.05)$ (table II) and there was a highly significant trend across weight groups $(p<0.0001)$. The striking increase in body mass index of siblings between the overweight and obese weight groups of adoptees was significant $(\mathrm{p}<0.01)$.

The figure shows the average body mass index of siblings for each of the four male-female combinations of adoptees and their full siblings. With a few exceptions the stepwise increase with weight group occurred in all combinations. The multiple regression analyses did not show any statistically significant two way or three way interaction effects between the weight groups of the adoptees and the sex of the adoptees and these siblings (parameter estimates not shown).

The maternal half siblings showed a monotonic increase in mean body mass index across the four weight groups (thin $22 \cdot 8$, medium $23 \cdot 1$, overweight $24 \cdot 1$, obese $24 \cdot 2$ ) (figure), and the trend was significant in the regression analysis $(p<0.002)$. Among the paternal half siblings the lowest mean body mass index was in the thin group $(23 \cdot 1)$, but the increase was not monotonic across the weight groups (medium $24 \cdot 0$,

TABLE I - Numbers of siblings in whom body mass index was known distributed by size of sibship, sex of siblings, and age of siblings in the four weight groups of adoptees

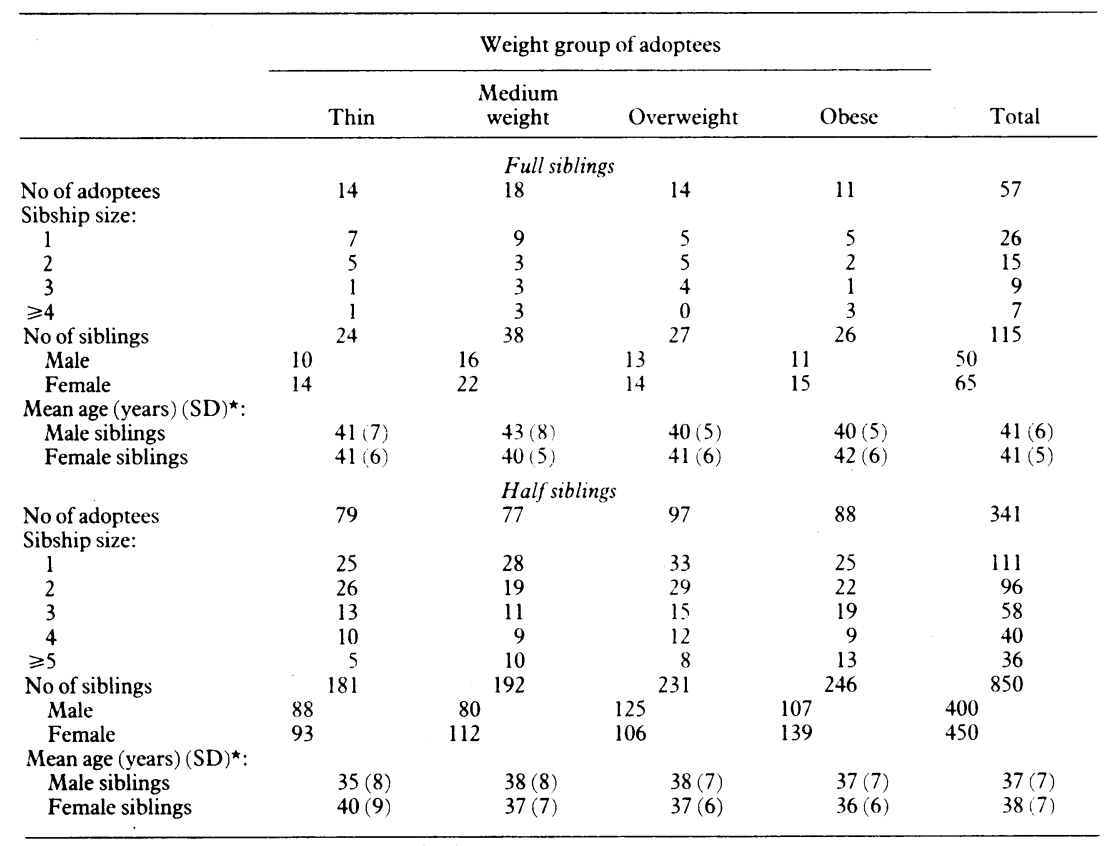

^Adjusted by weighting according to sibship size.
TABLE II - Multiple regression analyses of body mass index of siblings residuals after adjustment for age, weighted according to size of sibship) on weight groups of adoptees, sex of adoptees, sex of siblings, and (for half siblings) sex of common parent

\begin{tabular}{|c|c|c|c|}
\hline Variable & $\begin{array}{l}\text { Estimated } \\
\text { coefficient }\end{array}$ & $\begin{array}{l}\text { Standard } \\
\text { error }\end{array}$ & $\mathrm{p}$ Value \\
\hline \multicolumn{4}{|c|}{ Full siblings ${ }^{\star}$} \\
\hline Intercept & 3.09 & $1 \cdot 27$ & 0.02 \\
\hline \multicolumn{4}{|l|}{ Weight groupt: } \\
\hline Thin & $-4 \cdot 59$ & 0.97 & 0.0001 \\
\hline Medium & $-3 \cdot 98$ & 0.92 & 0.0001 \\
\hline Overweight & $-2 \cdot 73$ & 0.97 & $0 \cdot 006$ \\
\hline Female adoptee & $0 \cdot 31$ & 0.64 & 0.6 \\
\hline Female sibling & -0.13 & 0.64 & $0 \cdot 8$ \\
\hline \multicolumn{4}{|c|}{ Half siblings ${ }^{\star}$} \\
\hline \multirow{2}{*}{\multicolumn{4}{|c|}{ Weight groupt: }} \\
\hline & & & \\
\hline Thin & -1.04 & $0 \cdot 34$ & 0.003 \\
\hline Medium & $-0 \cdot 42$ & $0 \cdot 34$ & $0 \cdot 3$ \\
\hline Overweight & -0.39 & $0 \cdot 32$ & $0 \cdot 3$ \\
\hline Female adoptee & $0 \cdot 19$ & $0 \cdot 24$ & 0.5 \\
\hline Female sibling & -1.87 & $0 \cdot 24$ & 0.0001 \\
\hline Common mother & $0 \cdot 29$ & $0 \cdot 24$ & 0.3 \\
\hline
\end{tabular}

^Interaction effects within full and half sibling models (all non-significant) not shown.

tEach group estimated relative to obese group.

overweight $23 \cdot 5$, obese $23 \cdot 6$ ) (figure) and not significant in the analysis of trends. Neither type of half siblings showed the steep increase in body mass index between the overweight and obese groups seen in the full siblings.

In the regression analysis of all half siblings together the coefficients showed a steady increase in body mass index over the four weight groups of adoptees (table II); the trend across weight groups was significant $(\mathrm{p}<0.02)$, though the overall differences among weight groups were not. The obese group differed significantly only from the thin group $(p<0.02)$. The difference in trends across weight groups of adoptees between maternal and paternal half siblings was not significant (no significant two way interaction).

In both maternal and paternal half siblings the four combinations of male-female adoptees and malefemale half siblings showed no distinct differences in trends over the four weight groups (figure). The multiple regression analyses also disclosed no significant two, three, or four way interaction effects among the weight groups of adoptees and the eight combinations of sex of the adoptees, half siblings, and common parents (parameter estimates not shown).

\section{Discussion}

This report describes the first study of fatness of adoptees and their biological full and half siblings who were reared separately by the biological parents of the adoptees. It shows that the fatter the adoptees the greater was the body mass index of full siblings. There was a similar, weaker relation between adoptees and their half siblings. These results support those obtained with other methods ${ }^{5-15}$ and indicate a genetic influence on human fatness over the entire range from thinness to obesity. Further support for a specific genetic effect on obesity is suggested by the striking difference in body mass index between full siblings of obese and overweight adoptees that was not seen in half siblings or biological parents. No evidence was obtained for sex dependency of the relation in fatness between adoptees and their siblings.

All the studies of genetic influences on fatness have limitations. Comparison of identical and fraternal twins have suggested a genetic contribution to fatness, but such twin studies tend to overestimate genetic influence owing to the similarity of the environment of the identical twins. ${ }^{5132122}$ Fitting genetic models to family correlations in fatness also suggests a genetic contribution, ${ }^{6}$ but these analyses depend on assumptions about environmental influences and mode of 

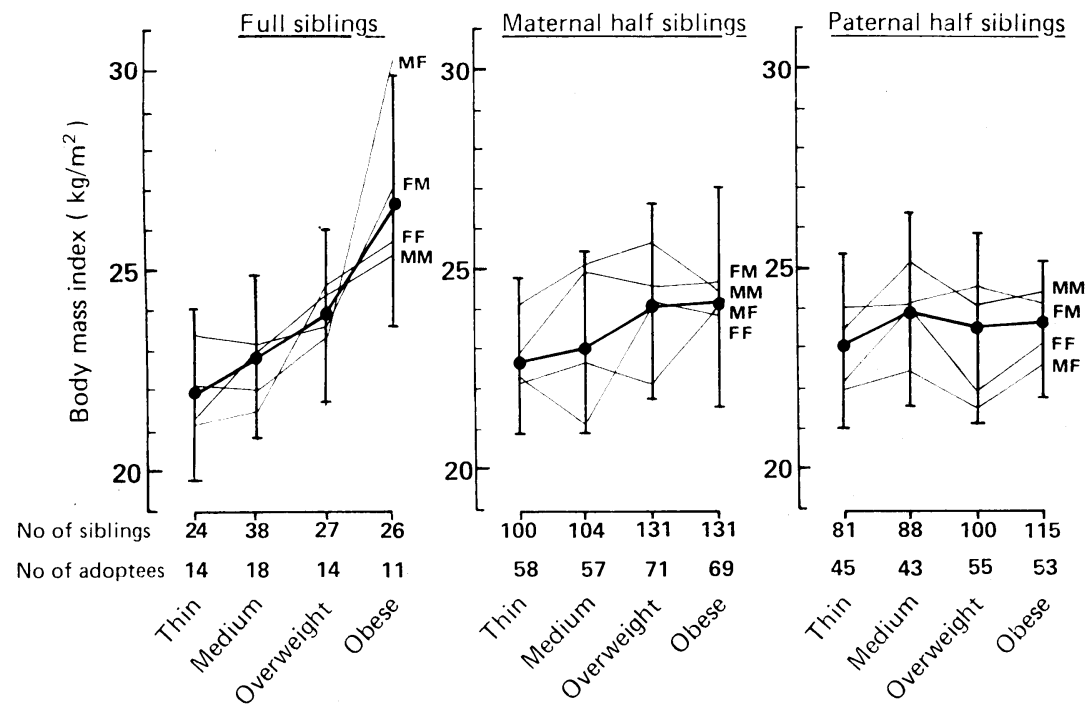

Body mass index (weighted according to size of sibship) of full siblings, maternal half siblings, and paternal half siblings in the four weight groups of adoptees. Heavy black points and bars are overall means and $S D$. Light plots are mean values for combinations of male adoptees/male siblings (MM), male adoptees/female siblings $(M F)$, female adoptees/male siblings ( $F M)$, and female adoptees/female siblings $(F F)$

inheritance-namely, polygenic inheritance of fatness. biological offspring with adoptees ${ }^{6-13}$ also suggested genetic influences, but as those studies did not examine genetic and environmental confounding could not be excluded.

Studies of adoptees and their natural parents ${ }^{1+15}$ are limited by difficulty in obtaining information about weights of parents and offspring at comparable periods The studies comparing adoptive parents and their the biological parents or siblings of the adoptees, not subject to these limitations. Nevertheless, they are in their lives ${ }^{2324}$ and by changes in environmental influences on fatness across the two generations. ${ }^{25} \mathrm{Our}$ study of biological siblings of adoptees who had not shared the family environment after being separated from their natural mothers was subject to neither of these limitations.

Even in adoptees there may have been an environmental effect on adult obesity from prenatal and postnatal factors such as early nutrition. ${ }^{2627}$ Stronger relations between mothers and offspring than between fathers and offspring would reflect early environmental effects, provided that transmission and expression of genetic effects were independent of sex.

Sex dependent genetic influences were suggested in our two previous adoption studies, ${ }^{14}$ is but those studies had methodological limitations. Both studies found stronger relations between biological mothers and offspring than between biological fathers and offspring. This result might be due to artefacts - for example, less reliable and less complete data on fathers' weight ${ }^{15}$ and uncertainty about paternity. Both studies also found stronger relations between parents and daughters than between parents and sons. Family studies, however, have not shown sex dependent differences in correlations between parents and offspring. ${ }^{2-46}$ The contribution of this study to resolving the question is limited by small sample sizes within the combined sex categories, especially among full siblings. Nevertheless, the study did not find any differences in genetic effects between men and women.

Our study offers an opportunity to assess maternal effects attributable to the early environment, which would produce a stronger association in fatness between adoptees and their maternal half siblings than between adoptees and their paternal half siblings. Our results do not definitely support or exclude the maternal effect. On the one hand, there was a significant trend among the maternal half siblings and none among the paternal half siblings. On the other hand, the difference between the trends was not significant, the sample included fewer paternal than maternal half siblings, and in this study also uncertainty about paternity may weaken the trend. Plainly, however, if the maternal effect exists it must be small. Furthermore, the difference between the full siblings and the maternal half siblings speaks for a stronger effect of genetics than early maternal environment. This conclusion accords well with the results from studies of natural families, which do not show appreciable maternal effects. ${ }^{246}$

It may be questioned whether the genetic influences on body mass index that we have found reflect genetic influences on fat or lean body mass, or both. Both fat and lean body mass are familial traits, ${ }^{1328}$ so that both traits may be subject to genetic influences. The differences in body mass index among the adoptees selected for our study undoubtedly reflected large differences in degree of fatness, but as fatness and lean body mass are highly correlated, ${ }^{29}$ they may also have differed in lean body mass. Though differences in lean body mass contributed to the differences among siblings, the size of the difference between siblings of overweight and obese adoptees suggests an important contribution of fat mass.

Polygenic transmission for the entire range from thin to obese is suggested by the association in body mass index between adoptees and full siblings. The finding that the association was stronger than that between adoptees and half siblings is also consistent with polygenic inheritance.

A major gene, or genes, might have a specific effect on obesity against a polygenic background. Such an effect is suggested by the significant difference in body mass index between full siblings of obese and overweight adoptees. No such difference was found among either half siblings or parents, ${ }^{14}$ though parents share half of their genes with their offspring, as do, on average, full siblings. One explanation of this pattern may be that full siblings share non-additive genetic effects for obesity. For example, obese adoptees may share pairs of rare recessive genes with their full siblings but only one allele with parents and one allele with about half of half siblings. Such a pattern of inheritance of obesity occurs in several species of rodents. ${ }^{30}$

In conclusion, though human fatness is influenced by the environment, as shown by differences between monozygotic twins ${ }^{7}$ and rapid changes over time in stable, homogeneous populations, ${ }^{25}$ it is clearly under substantial genetic control. The transmission appears to be independent of sex. We suggest that at least two modes of genetic inheritance are concerned-namely, polygenic inheritance for the full range of fatness and a major gene, or genes, specific for obesity.

This work was supported by grants from the NATO Science Fellowship Programme in Denmark (23-03 52/82) and the Danish Medical Research Council (12-7693) to TIAS; the National Institute of Arthritis, Metabolism, and Digestive Diseases (AM26607-01) to AJS; and the National Institute of Mental Health to RAP (MH43409) and AJS (career scientist awards MH00425 and MH31050). The work was also supported by the John D and Catherine T MacArthur Foundation to the Network on Health Promoting and Health Damaging Behavior. We are indebted to Drs Seymour Kety, David Rosenthal, and Paul Wender for permission to use the adoption register; to Margit Lyngby Christiansen, Anna-Lise Petersen, and Birgit Leth Jensen for help in data collection; and to Thomas W Teasdale and Craig L Hanis for data management.

1 Davenport CB. Body build and its inheritance. Washington, DC: Carnegie Institution, 1923. (Publication 329.

2 Garn SM, Clark DC. Trends in farness and the origins of obesity, Pediatrics 1976;57:443-56

3 Laskarzewski PM, Khoury P, Morrison JA, et al. Familial obesity and leanness. Int F Obes 1983;7:505-27.

4 Heller R, Garrison RJ, Havlik RJ, et al. Family resemblances in height and relative weight in the Framingham heart study. Int $\mathcal{O}$ Obes 1984;8:399-405.

Price RA. Genetics of human obesity. Annals of Behavioral Medicine 1987;9:9-14.

6 Longini IM, Higgins MW, Hinton PC, et al. Genetic and environmental sources of familial aggregation of body mass in Tecumseh, Michigan. Hum Biol 1984;56:733-57. 
7 Stunkard AJ, Foch TT, Hrubec Z. A twin study of human obesity. $7 \mathrm{AMA}$ 1986;256:51-4.

8 Withers RFJ. Problems in the generics of human obesity. Eugenics Review 1964:56:81-90.

9 Biron P, Mongeau JG, Bertrand D. Familial resemblance of body weight and weight/height in 374 homes with adopted children. $\mathcal{F}$ Pediatr 1977;91:555-8.

10 Garn SM, Cole PE, Bailey SM. Effects of parental fatness levels on the fatness of biological and adoptive children. Ecology of Food and Nutrition 1977; 6:91-4.

11 Hartz A, Giefer E, Rimm AA. Relative importance of the effects of family environment and heredity on obesity. Ann Hum Genet 1977;41:185-93.

12 Annest JL, Sing CF, Biron P, et al. Family aggregation of blood pressure and weight in adoptive families: III. Analysis of the role of shared genes and shared household environment in explaining family resemblance for height, weight and selected height/weight indices. Am f Epidemiol 1983; height, weight a

13 Bouchard C, Savard R, Despres J-P, et al. Body composition in adopted and biological siblings. Hum Biol 1985;57:61-75.

14 Stunkard AJ, Sorensen TIA, Hanis C, et al. An adoption study of human obesity. N Engl f Med 1986;314:193-8.

15 Price RA, Cadoret RJ, Stunkard AJ, et al. Genetic contributions to human fatness: an adoption study. Am $\mathcal{F}$ P sychiatry 1987;144:1003-8.

16 Kety SS, Rosenthal D, Wender PH, et al. The types and prevalence of mental illness in the biological and adoptive families of adopted schizophrenics. f Psychiatr Res 1967-8;6(suppl 1):345-62.

17 Teasdale TW. Social class correlations among adoptees and their biological and adoptive parents. Behav Genet 1979;9:103-14.

18 Sørensen TIA, Nielsen GG, Andersen PK, et al. Genetic and environmental influences on premature death of adult adoptees. $N$ Engl $\mathcal{F}$ Med 1988; 318:727-32.
19 Roche AF, Siervogel RM, Chumlea WC, et al. Grading body fatness from limited anthropometric data. Am f Clin Nutr 1981;34:2831-8.

20 Stunkard AJ, Albaum JM. The accuracy of self-reported weights. Am $\mathcal{F}$ Clin Nutr 1981;34:1593-9.

21 Feinleib M, Garrison RJ, Fabsitz R, et al. The NHLBI twin study of cardiovascular disease risk factors: methodology and summary of results. Am f Epidemiol 1977; 106:284-95.

22 Fabsitz RR, Garrison RJ, Feinleib M, et al. A twin analvsis of dietary intake: evidence for a need to control for possible environmental differences in $\mathrm{MZ}$ and DZ twins. Behav' Genet 1978;8:15-25.

23 Garn SM. Continuities and changes in fatness from infancy through adulthood.Curr Probl Pediatr 1985;15:1-47.

24 Sorensen TIA, Stunkard AJ, Teasdale TW, et al. The accuracy of reports of weight: children's recall of parents' weights 15 vears earlier. Int $\mathcal{F}$ Ohes 1983;7:115-22.

25 Sonne-Holm S, Sorensen TIA. Post-war course of the prevalence of extreme overweight among Danish young men. F Chronic Dis 1977;30:351-8.

26 Ravelli G-P, Stein ZA, Susser MW. Obesity in young men after famine exposure in utero and early infancy. $N$ Engl F Med 1976;295:349-53.

27 Charney E, Goodman HC, McBride M, et al. Childhood antecedents of adult obesity: Do chubby infants become obese adults? N Engl F Med 1976; 295:6-9.

28 Savard R, Bouchard C, Leblanc C, et al. Familial resemblance in fatness indicators. Ann Hum Biol 1983;10:111-8.

29 Owen OE, Holup JL, D'Alessio DA, et al. A reappraisal of the caloric requirements of men. Am f Clin Nutr 1987;46:875-85.

30 Bray G, York DA. Genetically transmitted obesity in rodents. Physiol Rev 1971;51:598-646.

(Accepted 3 October 1988

\section{Department of}

Epidemiology and Social

Oncology, University of Manchester, Manchester M20 9QL

Anne Charlton, PHD, director of Cancer Research Campaign education and child studies research group Valerie Blair, MSC, statistician

Correspondence to:

Dr Charlton.

\title{
Absence from school related to children's and parental smoking habits
}

\author{
Anne Charlton, Valerie Blair
}

\begin{abstract}
A sample of 2885 children aged 12 and 13 who completed a questionnaire survey in school in January 1987 were given a second questionnaire on a specified date in May 1987. The smoking habits, parental smoking habits, sex, and social background of the children who were present on both dates were compared with those of the children who were absent on the second occasion. Regular smoking was significantly more common among those absent for the second questionnaire: among boys 181/877 (21\%) who never smoked, $109 / 486(22 \%)$ who sometimes smoked, and $21 / 45(47 \%)$ who regularly smoked were absent, and among girls the figures were $157 / 947$ $(17 \%), 117 / 487(24 \%)$, and $17 / 43(40 \%)$ respectively Thus the odds ratio for those who sometimes smoked was 1.29 and for regular smokers 3.09 against those who never smoked. Whatever the children's smoking habits, the proportion who were absent was higher when both parents or at least the mother smoked, the odds ratio being 1.39; the proportions absent were $203 / 1180(17 \%)$ if neither parent or only the father smoked $v 135 / 644(21 \%)$ if both parents or only mother smoked for children who never smoked; $105 / 529(20 \%) v 121 / 444(27 \%)$ for those who sometimes smoked; and 10/27 (37\%) $v$ $28 / 61(46 \%)$ for those who regularly smoked. Sex and social background had little effect, though there was an overall higher rate of absence among boys from industrial areas.

The findings show a higher rate of minor ailments in children who smoke and in children whose mother smokes. If children are having frequent days off school for minor ailments possibly they or their parents would benefit from advice and help in stopping smoking.
\end{abstract}

\section{Introduction}

Over the past two decades evidence has accumulated not only that adults who smoke damage their health but also that children who smoke have various health problems. ${ }^{1-4}$ Many studies have shown associations between parental smoking and increased health problems in children, ${ }^{5-7}$ but many of these focused on children who did not themselves smoke. A few looked at the effects of smoking by both children and parents - for example, on respiratory diseases and on lung cancer in later life. ${ }^{910}$

We investigated whether absence from school for various reasons including minor ailments, such as colds, influenza, tonsillitis, and digestive disorders, of children aged 12 and 13 could be predicted on the basis of their own and their parents' smoking habits four months earlier.

\section{Subjects and methods}

As part of a study funded by the Cancer Research Campaign on the uptake of smoking we studied a random sample of 29 schools in Cumbria and Tyne and Wear. ${ }^{11}$ All the second year classes in these schoolsnamely, pupils aged 12 and 13-were included. The pupils were given two questionnaires: the first was administered during 12-16 January, and a second, identical questionnaire was completed by the same pupils during 18-22 May. The questionnaires were completed by the children under examination conditions supervised by their class teachers. This method has been shown to elicit the highest, and therefore presumably the most accurate, self reporting of smoking by adolescents. ${ }^{12}$ The children then sealed the anonymous questionnaires in plain envelopes to ensure confidentiality. The first and second questionnaires were matched by means of birth dates, information on school classes, and family data.

The children were asked to indicate their smoking habits by ticking one out of six possible replies. ${ }^{13}$ The six categories were: I have never smoked a cigarette; I have tried a cigarette once; I used to smoke but I don't smoke now; I smoke occasionally but not as much as one cigarette a week; I smoke between one and six cigarettes a week; and I usually smoke more than six cigarettes a week. To check the accuracy of the 